\title{
Epidemiology and Impact of Thoracic Trauma on the Mortality of Multi-trauma Patients: Results From a French Road Trauma Registry 1997-2016
}

Axel Benhamed ( $\sim$ axel.benhamed@chu-lyon.fr)

Hospices Civils de Lyon, Centre Hospitalier Universitaire Edouard Herriot

\section{Amina Ndiaye}

Université Gustave Eiffel, IFSTTAR

Marcel Emond

Centre Hospitalier Universitaire de Québec, Université Laval

Thomas Lieutaud

Université Gustave Eiffel, IFSTTAR

Marion Douplat

Hospices Civils de Lyon, Centre Hospitalier Universitaire Lyon Sud

Amaury Gossiome

Hospices Civils de Lyon, Centre Hospitalier Universitaire Edouard Herriot

\section{Bernard Laumon}

Université Gustave Eiffel, IFSTTAR

Blandine Gadegbeku

Université Gustave Eiffel, IFSTTAR

Karim Tazarourte

Hospices Civils de Lyon, Centre Hospitalier Universitaire Edouard Herriot

\section{Research Article}

Keywords: road traffic accident (RTA), thoracic trauma, multi-trauma patients, thoracic injuries

Posted Date: September 17th, 2021

DOl: https://doi.org/10.21203/rs.3.rs-855268/v1

License: (c) (i) This work is licensed under a Creative Commons Attribution 4.0 International License.

Read Full License 


\section{Abstract}

Thoracic trauma is the third most common cause of death in multi-trauma patients. One of the most frequent mechanism is road traffic accident (RTA). The objective of the present study was to investigate the influence of severe (abbreviated injury scale, AIS $\geq 3$ ) injuries in each body region on the mortality of multi-trauma patients with a particular attention to thoracic trauma. We also described the epidemiology and injury pattern of these patients when presenting with at least one AIS $\geq 2$ thoracic injury

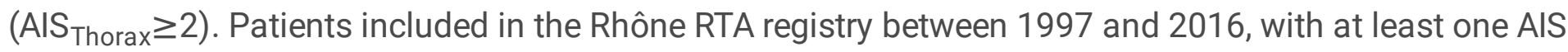
$\geq 2$ injury in any body region were included. Two subgroups were defined according to whether patients presented at least one AIS Thorax $\geq 2$ injury or not. Multivariate regression analysis with mortality as outcome was performed. A total of 46,526 patients had at least one AIS $\geq 2$ injury, among them 6,382 (13.7\%) had at least one $\mathrm{AIS}_{\text {Thorax }} \geq 2$ injury. Severe thoracic injuries (OR=12.2, 95\% $\left.\mathrm{Cl}[8.4 ; 17.7]\right)$ were strongly associated with death, second to severe head injuries were $(\mathrm{OR}=26.8,95 \% \mathrm{Cl}[20.4 ; 35.2])$. Chest wall injuries were the most frequent thoracic injury $(62.1 \%, n=5,419)$ and $52.4 \%$ of these were multiple rib fractures. Severe thoracic injury is a priority in multi-trauma patients; both in the detection but also in the management.

\section{Introduction}

Road traffic accidents (RTA) were the tenth leading cause of death in the world in 2000 , the eighth in 2016, and could become the fifth by 2030 according to the World Health Organization; it affects in particular those aged 5 to 44 years ${ }^{1,2}$. Victims of RTA often suffer multi-trauma and present with thoracic injuries in nearly $50 \%$ cases $^{3}$. Furthermore, thoracic trauma is the third most common cause of death after abdominal injury and head trauma in multi-trauma patients ${ }^{4}$. Thoracic injuries are associated with poor short-term outcomes since there are responsible for up to $25 \%$ of trauma-related deaths ${ }^{5,6}$ and also poor long-term outcome; for example, persistent reduced 6-min walk distance, impaired pulmonary function, and reduced pulmonary-specific quality of life ${ }^{7}$. Hence, thoracic trauma represents a major medical and economic matter of concern, and a challenge to provide better care. Risk factors for mortality after thoracic trauma, including the influence of specific structural damages of the chest wall and thoracic organs on mortality have been investigated ${ }^{6,8,9}$. Furthermore, many studies have shown that thoracic injuries significantly contribute to the mortality of multi-trauma patients, in adults as well as in the paediatric population ${ }^{10-12}$. However, to the best of our knowledge, no study has investigated specifically the influence of severe injuries (abbreviated injury scale, AIS $\geq 3$ ) in each body region in multitrauma patients' mortality. The primary objective of the present study was therefore to investigate and compare the influence of severe injuries in each body region on the mortality of multi-trauma patients, more specifically to thoracic region. Secondary objective was to describe the epidemiology and injury pattern of these patients when presenting with at least one AIS $\geq 2$ thoracic injury (AIS Thorax $\geq 2$ ).

\section{Methods}




\section{Study setting}

This study used prospectively-recorded data from the Rhône RTA registry (Registre des victimes d'accidents de la circulation du Rhône) set up in 1995. The registry covers the Rhône area of France (1.83 million inhabitants, 676 inhabitants $/ \mathrm{km}^{2}$ ). It is part of the Gustave Eiffel university, Lyon. The registry team supervise the centralization, verification of the data from different sources about the same accident or victim, coding, storage and filing, and statistical analysis. The registry inclusion criteria are as follows: a RTA involving at least one vehicle (motorised or not) occurring in the Rhône area, requiring institutional healthcare from one of the 245 private and public healthcare structures cooperating together, including prehospital primary care teams and forensic medicine institutes. Each injury was coded according to the AIS (version 1990 for years 1996 to 2014, and version 2005 for years 2015 and 2016) which is a severity score, ranging from 1 (minor) to 6 (beyond treatment) ${ }^{13}$

The injury severity score (ISS) was calculated from the three worst-affected body regions as the sum of squares of the respective AIS severity levels. Road users were divided into five categories: car occupants, motorcyclists, bicyclists, pedestrians, and other road users (roller skaters, skate boarders, bus occupants, truck occupants etc.). Death was medically certified at the scene or noted in medical charts during hospital stay. An autopsy was systematically undertaken in patients dying in the prehospital setting to ensure the cause of death and provide a complete injury assessment based on AIS scoring

\section{Study design}

We conducted a retrospective study that included RTA occurring during the period from January 1997 to December 2016. As victims could suffer from several injuries in each body region, the maximum AIS (MAIS) was scored using the injury of the highest severity.

\section{Data collection}

The registry collects the demographic characteristics of each RTA casualty and a description of the body injuries sustained. Data are collected prospectively in three consecutive time periods from the accident site until hospital discharge: prehospital scene, emergency room or intensive care unit, and discharge. Several variables were extracted and analysed: patient characteristics (sex, age, road user category), road network, anatomical injuries, severity score (AIS and ISS), and outcome (intensive care unit admission and mortality). Data collection method has been described previously ${ }^{14}$.

\section{Study participants}

Inclusion criteria for the present study were patients of all ages included in the registry, with at least one AIS $\geq 2$ injury in any body region (AIS $\geq 2$ group). We excluded patients if they had suffered severe burn injury. Two subgroups were defined: AIS $\mathrm{Thorax} \geq 2$ group included all patients from AIS $\geq 2$ group suffering from at least one thoracic AIS $\geq 2$ injury, and $\mathrm{AIS}_{\text {Thorax }}<2$ group included those who did not. There was no exclusion criterion. 


\section{Statistical analysis}

Baseline characteristics were described by frequencies and percentages for categorical variables, and medians and interquartile range [IQR] for continuous variables. Comparisons between groups were made using the Pearson $\mathrm{Chi}^{2}$ test for categorical variables. We then performed a logistic regression with mortality as outcome. Significant prognostic variables at $5 \%$ significance on the univariate analysis were included in analysis. The odds ratio (OR) for each risk factor investigated was calculated as well as the corresponding $95 \%$ confidence intervals $(\mathrm{Cl})$. Statistical analyses were performed using SAS (Statistical Analysis System v9.4, SAS Institute Inc., Cary, NC, USA). In all analyses, $p<0.05$ was considered as statistically significant.

\section{Ethics approval and consent to participate}

The registry and has been approved by the relevant national authorities (Comité National des Registres, $\mathrm{CNR}$ ) and data protection agency and (Commission Nationale de l'Informatique et des Libertés, CNIL; $\mathrm{N}^{\circ}$ 999211) which waived the need to obtain informed consent from the study participants given the retrospective and anonymized nature of this study in routine care. All methods were conducted in accordance with relevant guidelines and regulations (the ethical standards of the 1964 Declaration of Helsinki and its later amendments or comparable ethical standards).

\section{Results}

\section{Patient and injury characteristics}

Over the study period, a total of 176,346 victims were included in the registry; $46,526(26.4 \%)$ had at least one AIS $\geq 2$ injury and were included in the present study (AIS $\geq 2$ group). Among these, 6,382 (13.7\%) had at least one thoracic injury AIS $_{\text {Thorax }} \geq 2$ (AIS Thorax $\geq 2$ group). The median [IQR] age was greater in the AIS Thorax $\geq 2$ group (41 [25-58] years) than in the AIS Thorax $_{\text {Th }}$ group (26 [18-42] years, $\left.p<0.001\right)$, and there were more females $(31.1 \%$ vs. $26.9 \%, p<0.001)$. There was a difference in the distribution of road users $(p<0.001)$ and road network $(p<0.001)$ between those groups; in the AlS ${ }_{\text {Thorax }} \geq 2$ group patients were more frequently car occupants ( $52.3 \%$ vs $23.4 \%$ ) and RTA occurred more frequently on a highway $(11.3 \%$ vs $5.7 \%$ ) or a rural road ( $23.4 \%$ vs $10.6 \%$; Table 1$)$. Among females in the AIS Thorax $\geq 2$ group, the maximal incidence of RTA was in the 70-79 years age group (23.1/100,000 inhabitants) and this was found in the 20-29 years age group among males (39.1/100,000 inhabitants; Fig.1). The distribution of road user by age group is reported in the Fig. 2 .

In the IIS $_{\text {Thorax }} \geq 2$ group, the median [IQR] ISS was 14 [6-27], 30.8\% $(n=1,968)$ of patients were admitted to an intensive care unit, and $16.2 \%(n=1,031)$ patients died. Of these patients, $61.5 \%(634 / 1,031)$ died onscene; among those admitted to hospital $(38.5 \%, n=397), 37.3 \%(n=148 / 397)$ died during the first 24 hours, and $75.6 \%$ ( $n=300 / 397)$ did so within the first three days. Thoracic injuries were the cause of death for $42.7 \%(440 / 1,031)$ victims. According to the road user category, pedestrians had the highest mortality 
$(30.6 \%, 207 / 677)$; there were $17.6 \%(285 / 1,617)$ deaths among motorcyclists, $13.6 \%(455 / 3,337)$ deaths among car occupants, $12.2 \%$ (38/312) among other road users and $10.5 \%(46 / 439)$ deaths among bicyclists. There were $1.4 \%(36 / 2,541)$ of patients with MAIS Thorax $=2$ who died, $7.9 \%(164 / 2,084)$ with MAIS Thorax $=3$ died, and $47.3 \%(831 / 1757)$ patients with MAIS $_{\text {Thorax }} \geq 4$ died.

\section{Risk factors for mortality}

Severe head injuries conferred the highest risk of death (OR=26.8,95\% Cl [20.4;35.2]), and severe thoracic injuries were strongly associated with death $(\mathrm{OR}=12.2,95 \% \mathrm{Cl}[8.4 ; 17.7])($ Table 2$)$.

\section{Injury pattern}

The most frequent thoracic injury was that of the chest wall $(62.1 \%, n=5,419) ; 52.4 \%$ of these were multiple rib fractures. The second most frequent thoracic injury was that of the lung $(24.7 \%, n=2,158)$; $88.7 \%$ of these were lung contusions. Pleural injuries (including pneumothorax and haemothorax) was found in $5.3 \%(n=466)$ of cases (Table 3). The frequency of MAIS Thorax $=2$ injuries increased with age while that of MAIS Thorax $=3$ injuries decreased (Fig. 3). Among those with a thoracic injury, $29.1 \%$ suffered concomitant AIS $\geq 2$ head trauma, $26.8 \%$ upper extremity injuries, and $25.8 \%$ lower extremity injuries; in addition, $17.9 \%$ suffered concomitant AIS $\geq 2$ abdomen and pelvis injuries, $16.3 \%$ spine injuries, $7.5 \%$ face injuries, $1.1 \%$ neck injuries, and $0.08 \%$ skin injuries (Table 4 ).

\section{Discussion}

In the present study severe thoracic trauma showed a strong impact on patient mortality, but lower than severe head trauma. The odds ratios for death in the multivariate analysis were quite similar for thoracic, facial, and abdominal/pelvic traumas. In addition, three-quarters of those with a severe thoracic trauma and who died did so within the first 24 hours. Surprisingly, Grubmüller et al. found that the presence of a severe thoracic trauma had no influence on mortality ${ }^{15}$, contrary to that found herein results and other previous investigations ${ }^{9}$. They hypothesized that this finding could be led by the high case load of their level I trauma centre (>100/centre) whereas our study included level I to III trauma centres. Indeed, some authors suggested that the hospital volume of severely injured patients may be an independent predictor of survival ${ }^{16,17}$. Furthermore, their results are based on a single-centre experience where penetrating trauma and patients suffering unsuccessful emergency resuscitation were excluded. In the present study, road network (highway and rural road compared to city street), road user (car occupant) and being a male were significantly associated with a higher risk of death while trauma severity (AIS) was included in the multivariate analysis. Because we dichotomised level of severity in two groups (AIS $=2$ vs AIS $\geq 3$ ), the distribution of AIS $\geq 3$ could not be homogenous between road network categories, user categories and sex and could resulted in higher frequency of severe (AIS 4), critical (AIS 5) and beyond treatment (AIS 6) injuries in some groups among previous cited categories which could explain our results. 
In the present study, mortality was similar to what is reported elsewhere, Grubmüller et al. reported mortality was $13.2 \%{ }^{15}$, Huber et al. reported a $17.5 \%$ mortality ${ }^{9}$ and Veysi et al. mortality was $18.7 \%$ in their cohort ${ }^{5}$. In contrast, in the German multicentre database TraumaRegister DGU ${ }^{\circledR}$, Horst et al.. ${ }^{18}$ reported an overall mortality rate around $5 \%$ in their 10 -year-period study. So did Chrysou et al. with a reported mortality of $5.5 \% .{ }^{12}$ However, only patients reaching the hospital with vital signs were included whereas in the present study we did not exclude on-scene dead patients. If we had excluded these patients, we would have found a mortality rate of $6.2 \%$. One strength of the present study was the inclusion of on-scene deceased patients without inducing any misclassification bias because an autopsy was systematically undertaken in those patients to ensure the cause of death and provide a complete injury assessment based on AIS scoring.

The present study found a lower incidence of thoracic trauma compared to that reported elsewhere $9,19,20$. This was probably underestimated herein as those suffering minor thoracic injuries ( IIS $_{\text {Thorax }}=1$ ), including single rib fractures, were not considered. Peek et al. recently reported in their nationwide studies that single rib fracture were frequently encountered injuries ( $20 \%$ of rib fractures) ${ }^{21,22}$. We chose not to include these patients because previous studies have demonstrated that these single rib fractures were not associated with mortality ${ }^{9}$. We also noted that Chrysou et al. reported lower incidence of sternal fracture (15.5\%) but a higher incidence of concomitant spine injuries (53.6\%); which may be explained by the inclusion of patients suffering fall from height and snow sport accidents in their study ${ }^{12}$ which have been previously reported as a significant source of traumatic spinal cord injuries ${ }^{23,24}$.

Another interesting finding of the present study is the evolution of AIS Thorax 2 and 3 with age. AIS 3 injuries incidence was the highest in children (0-9 years) and decreased with age. This is in line with Samarasekera et al. findings reported a very high incidence of AIS $>2$ injuries (88\%) among children (<15years) thoracic injuries with $65 \%$ of them being lung contusions ${ }^{25}$ and Ostermann et al. recently reported half of thoracic injuries being lung contusions (AIS 3$)^{11}$. One explanation is the difference in anatomy; the thoracic skeleton of children being incompletely calcified and more compressible allowing for the transmission of large forces to the structures of the thoracic cavity, making rib fractures uncommon. Thus, high-energy impact trauma may cause major internal injuries with little evidence of external injuries or fractures of the bony thorax as reported by many authors $11,26,27$. Furthermore, as children are more frequently involved in RTA as pedestrians they may be at higher risk of projection and severe trauma caused by direct impact with the front bumper because of their smaller height. In contrast, the incidence of AIS $=2$ thoracic injuries incidence increased with age. These injuries are mainly rib fractures. which, in the elderly, have been reported as the most frequent after a RTA ${ }^{28}$. They required less force compared to young patients because of osteoporosis and loss of muscle mass.

This study has a number of limitations. One of them is the update of AIS during the study period ${ }^{29}$. Nevertheless, we chose to base severity assessment on AIS because it has been extensively used in the literature and is an accurate, objective and validated method to independently evaluate each body region impact on mortality ${ }^{30}$ contrary to the ISS that evaluates the overall severity ${ }^{31}$. Besides, Hsu et al. ${ }^{32}$ 
found that the AIS update had no impact on mean ISS when considering the thoracic body region. Although it is a register study with the known weaknesses, the present multicentre study is based on data prospectively collected over a 20-year-period from level I to III trauma centres and included patients of all ages whereas many studies focused on thoracic trauma are single centre studies and only included patients $\geq 16$ years $5,8,12,15,19,33$. Thus, our findings are generalisable to other high-income countries. Besides, data were collected by emergency physicians, blinded to which of the risk factors and outcomes were being used in the present study. Another limitation is that the Rhône registry only includes victims of RTA. Therefore, the registry represents a trauma population with a majority of blunt trauma and other reported thoracic mechanisms such as falls, or stab/fire gun injuries, have not been studied here. Also, the objective relies on an anatomic system of injury classification (AIS and ISS) since the database does not report physiological assessment nor medical management. There is therefore no data regarding prehospital management, time to surgery when needed, intensive care unit management such as airway and ventilation management, use of vasopressors or massive blood transfusion, and no detail on organ and respiratory failure or pre-existing cardiopulmonary disease which have been reported to influence outcome in thoracic trauma patients ${ }^{6,8,9,15}$. The value of anatomic scoring systems in outcome prediction of trauma patients has been debated and compared to physiologic scores. Some authors found ISS to be a best severity predictor compared to the revised Trauma Scale (RTS) and the simplified acute physiology scale II (SAPS II) ${ }^{34}$. Hence, we believe that using anatomic scoring in the present study is as efficient as physiologic scoring in predicting outcomes.

\section{Conclusion}

The present study found that the severity of thoracic trauma was an independent and significant risk factor for death in multi-trauma patients.

\section{Declarations}

\section{Data availability}

The datasets during and/or analyzed during the current study available from the corresponding author on reasonable request.

\section{Acknowledgments}

The authors would like to thank Philip Robinson (DRS, Hospices Civils de Lyon, Lyon, France) for help in manuscript preparation and everyone who participated in the data collection

\section{Contributions}

AB: conceptualization, methodology, writing-original draft. AN: formal analysis, investigation. ME: Writing - Review \& Editing. TL: Writing - Review \& Editing. MD: Writing - Review \& Editing. AG: Writing - Review \& 
Editing. BL: project administration, Writing - Review \& Editing, ressources. BG: formal analysis, Writing Review \& Editing. KT: conceptualization, methodology, writing-original draft, supervision.

\section{References}

1. World Health Organization \& issuing body. Global status report on road safety 2018. (2018).

2. World Health Organization. Global status report on road safety 2013: supporting a decade of action (WHO, 2013).

3. Vécsei, V., Arbes, S., Aldrian, S. \& Nau, T. Chest Injuries in Polytrauma. Eur J Trauma Emerg Surg, 31, 239-243 (2005).

4. Angelos, M. G. et al. Cardiovascular response to epinephrine varies with increasing duration of cardiac arrest. Resuscitation, 77, 101-110 (2008).

5. Veysi, V. T., Nikolaou, V. S., Paliobeis, C., Efstathopoulos, N. \& Giannoudis, P. V. Prevalence of chest trauma, associated injuries and mortality: a level I trauma centre experience. Int Orthop, 33, 14251433 (2009).

6. Battle, C. E., Hutchings, H. \& Evans, P. A. Risk factors that predict mortality in patients with blunt chest wall trauma: A systematic review and meta-analysis. Injury, 43, 8-17 (2012).

7. Leone, M. et al. Long-term outcome in chest trauma., 109, 864-871 (2008).

8. Battle, C. E. et al. Predicting outcomes after blunt chest wall trauma: development and external validation of a new prognostic model. Crit Care, 14, 18 (2014).

9. Huber, S. et al. Predictors of poor outcomes after significant chest trauma in multiply injured patients: a retrospective analysis from the German Trauma Registry (Trauma Register DGU®). Scand J Trauma Resusc Emerg Med, 22, 52 (2014).

10. TraumaRegister, D. G. U. et al. Thoracic trauma severity contributes to differences in intensive care therapy and mortality of severely injured patients: analysis based on the TraumaRegister DGU®. World J Emerg Surg.12, (2017).

11. Ostermann, R. C. et al. Thoracic Injuries in Pediatric Polytraumatized Patients: Epidemiology, Treatment and Outcome. Injury, 52, 1316-1320 (2021).

12. Chrysou, K., Halat, G., Hoksch, B., Schmid, R. A. \& Kocher, G. J. Lessons from a large trauma center: impact of blunt chest trauma in polytrauma patients-still a relevant problem? Scand J Trauma Resusc Emerg Med.25, (2017).

13. Loftis, K., Price, J. \& Gillich, P. P. Evolution of the abbreviated injury scale:1990-2015. Traffic Inj Prev, 19,, S109-S113 (2018).

14. Paparel, P. et al. The epidemiology of trauma of the genitourinary system after traffic accidents: analysis of a register of over 43000 victims. BJU Int, 97, 338-341 (2006).

15. Grubmüller, M. et al. Severe thoracic trauma - still an independent predictor for death in multiple injured patients? Scand J Trauma Resusc Emerg Med, 26, 6 (2018). 
16. Sewalt, C. A. et al. The volume-outcome relationship in severely injured patients: A systematic review and meta-analysis. J Trauma Acute Care Surg, 85, 810-819 (2018).

17. Zacher, M. T. et al. Association between volume of severely injured patients and mortality in German trauma hospitals. Br J Surg, 102, 1213-1219 (2015).

18. Horst, K. et al. Thoracic trauma now and then: A 10 year experience from 16,773 severely injured patients. PLoS One, 12 (10), e0186712 (2017).

19. Beshay, M. et al. Analysis of risk factors in thoracic trauma patients with a comparison of a modern trauma centre: a mono-centre study. World J Emerg Surg, 15, 45 (2020).

20. TraumaRegister, D. G. U. et al. Severity-dependent differences in early management of thoracic trauma in severely injured patients - Analysis based on the TraumaRegister DGU®.Scand J Trauma Resusc Emerg Med.25, (2017).

21. Peek, J. et al. Traumatic rib fractures: a marker of severe injury. A nationwide study using the National Trauma Data Bank. Trauma Surg Acute Care Open, 5, e000441 (2020).

22. Peek, J. et al. Epidemiology and outcome of rib fractures: a nationwide study in the Netherlands. Eur J Trauma Emerg Surg.(2020).

23. Chen, Y., He, Y. \& DeVivo, M. J. Changing Demographics and Injury Profile of New Traumatic Spinal Cord Injuries in the United States, 1972-2014. Arch Phys Med Rehabil, 97, 1610-1619 (2016).

24. Chan, C. W., Eng, J. J., Tator, C. H. \& Krassioukov, A. \& the Spinal Cord Injury Research Evidence Team. Epidemiology of sport-related spinal cord injuries: A systematic review. J Spinal Cord Med, 39, 255-264 (2016).

25. Samarasekera, S. P., Mikocka-Walus, A., Butt, W. \& Cameron, P. Epidemiology of major paediatric chest trauma. J Paediatri Child Health, 45, 676-680 (2009).

26. Balcı, A. E. et al. Blunt thoracic trauma in children: review of 137 cases. Eur J Cardiothorac Surg, 26, 387-392 (2004).

27. Bliss, D. \& Silen, M. Pediatric thoracic trauma. Crit Care Med, 30, S409-S415 (2002).

28. Lee, W. Y., Yee, W. Y., Cameron, P. A. \& Bailey, M. J. Road traffic injuries in the elderly. Emerg Med J, 23, 42-46 (2006).

29. Loftis, K. L., Price, J. \& Gillich, P. J. Evolution of the Abbreviated Injury Scale: 1990-2015. Traffic Inj Prev, 19, S109-S113 (2018).

30. Clarke, J. R., Ragone, A. V. \& Greenwald, L. Comparisons of survival predictions using survival risk ratios based on International Classification of Diseases, Ninth Revision and Abbreviated Injury Scale trauma diagnosis codes. J Trauma, 59, 563-567 (2005).

31. Baker, S. P., O’Neill, B., Haddon, W. \& Long, W. B. The injury severity score: a method for describing patients with multiple injuries and evaluating emergency care. J Trauma, 14, 187-196 (1974).

32. Hsu, S. Y. et al. Impact of Adapting the Abbreviated Injury Scale (AIS)-2005 from AIS-1998 on Injury Severity Scores and Clinical Outcome.Int J Environ Res Public Health.16, (2019). 
33. Söderlund, T., Ikonen, A., Pyhältö, T. \& Handolin, L. Factors associated with in-hospital outcomes in 594 consecutive patients suffering from severe blunt chest trauma. Scan J Surg, 104, 115-120 (2015).

34. Kahloul, M. et al. Value of anatomic and physiologic scoring systems in outcome prediction of trauma patients. Eur J Emerg Med, 21, 125-129 (2014).

\section{Tables}

Table 1. Demographics and mechanism Statistics presented: $\mathrm{n}(\%) ;$ median [IQR] 


\begin{tabular}{|c|c|c|c|c|}
\hline & $\begin{array}{l}\text { AIS } \geq 2 \\
\text { group } \\
(n=46,526)\end{array}$ & $\begin{array}{l}\text { AIS }_{\text {Thorax }} \geq 2 \\
\text { group }(n=6,382)\end{array}$ & $\begin{array}{l}\text { AIS }_{\text {Thorax }} 2 \\
\text { group }(n=40,144)\end{array}$ & $\begin{array}{l}\mathrm{p}- \\
\text { value }\end{array}$ \\
\hline Age, years & 28 [18-45] & 41 [25-58] & 26 [18-42] & \multirow[t]{8}{*}{$<0.001$} \\
\hline $0-9$ & 2,468 (5.3) & $93(1.5)$ & 2,375 (5.9) & \\
\hline $10-19$ & $\begin{array}{l}11,066 \\
(238)\end{array}$ & $658(10.3)$ & $10,408(25.9)$ & \\
\hline $20-39$ & \multirow{2}{*}{$\begin{array}{l}18,084 \\
(38.9)\end{array}$} & $2,246(35.2)$ & $15,838(39.5)$ & \\
\hline $40-59$ & & $1,930(30.2)$ & 7,878 (19.6) & \\
\hline $60-79$ & $9,808(21.1)$ & $1,157(18.1)$ & $2,912(7.3)$ & \\
\hline \multirow[t]{2}{*}{$\geq 80$} & 4,069 (8.7) & \multirow[t]{2}{*}{$291(4.6)$} & \multirow[t]{2}{*}{695 (1.7) } & \\
\hline & $986(2.1)$ & & & \\
\hline \multicolumn{4}{|l|}{ Sex } & \multirow[t]{3}{*}{$<0.001$} \\
\hline Male & \multirow{2}{*}{$\begin{array}{l}33,738 \\
(72.5) \\
12,778 \\
(27.4)\end{array}$} & \multirow{2}{*}{$\begin{array}{l}4,400(68.9) \\
1,982(31.1)\end{array}$} & \multirow{2}{*}{$\begin{array}{l}29,338(73.0) \\
10,796(26.9)\end{array}$} & \\
\hline Female & & & & \\
\hline Road user & & & & $<0.001$ \\
\hline Car occupant & $\begin{array}{l}12,739 \\
(27.4)\end{array}$ & $3,337(52.3)$ & $9,402(23.4)$ & \\
\hline Pedestrian & \multirow{3}{*}{$\begin{array}{l}6,011(12.9) \\
8,783(18.9)\end{array}$} & 677 (10.6) & 5,334 (13.3) & \\
\hline Bicyclist & & 439 (6.9) & $8,344(20.8)$ & \\
\hline Motorcyclist & & $1,617(25.3)$ & $12,880(32.1)$ & \\
\hline \multirow[t]{2}{*}{ Other } & \multirow{2}{*}{$\begin{array}{l}14,497 \\
(31.2) \\
4,496(9.6)\end{array}$} & $312(4.9)$ & $4,184(10.4)$ & \\
\hline & & & & \\
\hline $\begin{array}{l}\text { Road } \\
\text { network }\end{array}$ & & & & \multirow[t]{5}{*}{$<0.001$} \\
\hline City street & $\begin{array}{l}26,238 \\
(56.4)\end{array}$ & 3,361 (52.7) & $22,877(57.0)$ & \\
\hline Highway & $3,006(6.5)$ & & $2,283(5.7)$ & \\
\hline Rural road & $5,745(12.3)$ & $1,497(23.4)$ & 4,248 & \\
\hline Other & $\begin{array}{l}11,537 \\
(24.8)\end{array}$ & $801(12.0)$ & $10,730(20.1)$ & \\
\hline
\end{tabular}

AIS $\geq 2$ group $_{2}$ : multi-trauma patients presenting with at least one injury AIS $\geq 2$, 
$A_{\text {IS }} S_{\text {Thora }} \geq 2$ group: multi-trauma patients presenting with at least one thoracic injury AIS $\geq 2$, AIS $_{\text {Thorax }}<2$ group $_{2}$ : multi-trauma patients presenting with at least one injury AIS $\geq 2$ but not in the thoracic region; AIS: abbreviated injury scale

Table 2. Predictors of mortality in univariate and multivariate analysis in AIS $\geq 2$ group

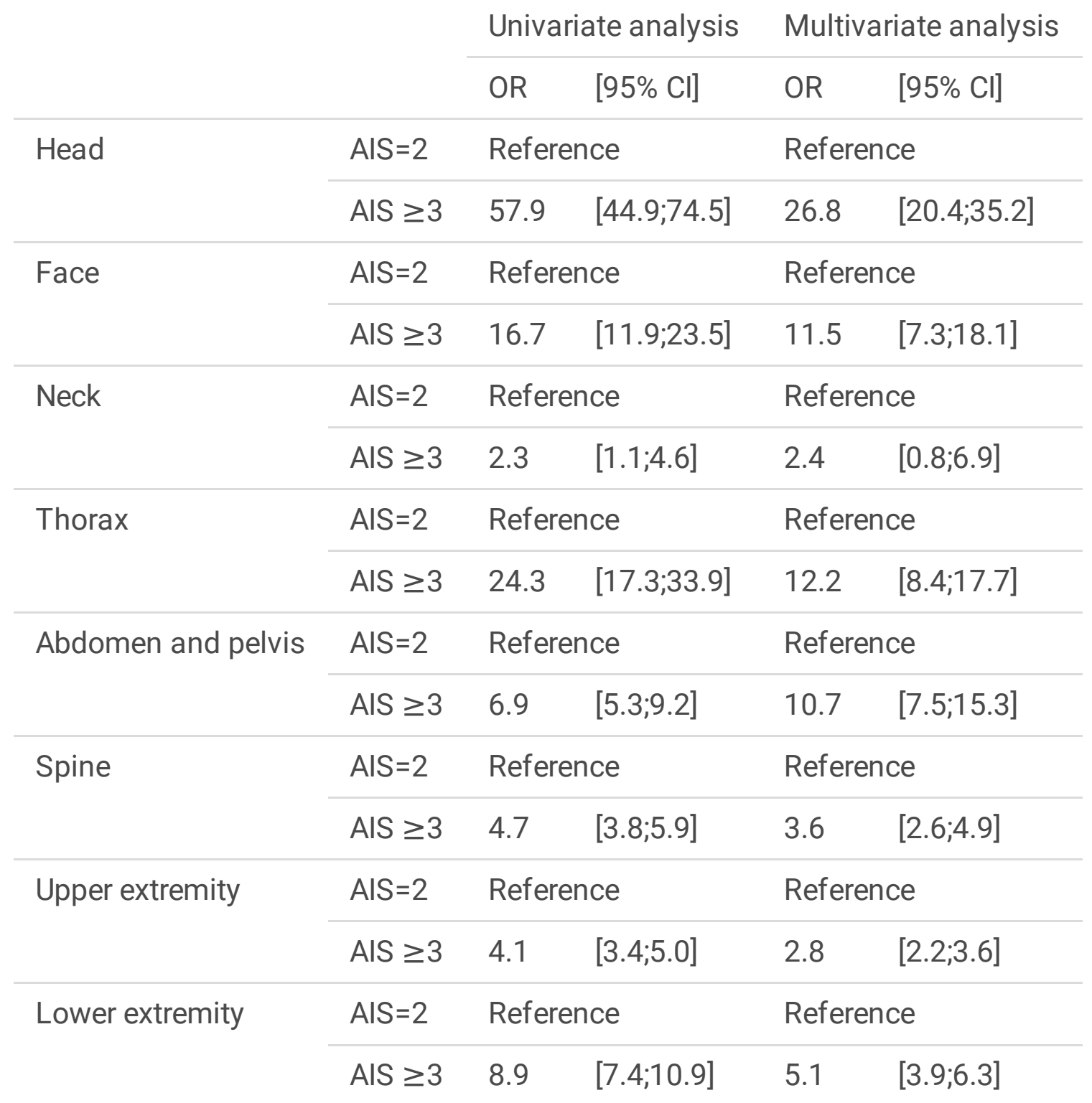

AIS $\geq 2$ group: multi-trauma patients presenting with at least one injury AIS $\geq 2$, AIS: abbreviated injury scale. $p<0.05$ for all variables in the univariate analysis

Table 3. Description of thoracic injuries in the $\mathrm{AlS}_{\text {Thorax }} \geq 2$ group 


\begin{tabular}{|ll|}
\hline Chest wall injuries & $5,419 / 8,729(62.1)$ \\
Multiple rib fracture & $2,842 / 5,419(52.4)$ \\
Sternal fracture & $1,719 / 5,419(31.7)$ \\
Flail chest & $478 / 5,419(8.8)$ \\
Single rib fracture & $276 / 5,419(5.1)$ \\
Other & $104 / 5,419(2)$ \\
\hline Lung injuries & $2,158 / 8,729(24.7)$ \\
Pulmonary contusion & $1,914 / 2,158(88.7)$ \\
Pulmonary laceration & $244 / 2,158(11.3)$ \\
\hline Pleural and mediastinal injuries & $466 / 8,729(5.3)$ \\
Pneumo and/or haemothorax & $352 / 466(75.5)$ \\
Pneumo and/or haemomediastinum & $105 / 466(22.5)$ \\
Other & $9 / 466(2)$ \\
\hline Cardiac or vascular injuries & $421 / 8,729(4.8)$ \\
Cardiac & $227 / 421(54)$ \\
Thoracic aorta & $120 / 421(28.5)$ \\
Pulmonary arteries/veins & $46 / 421(11)$ \\
Coronary artery & $12 / 421(2.9)$ \\
Subclavian artery/vein & $10 / 421(2.4)$ \\
Other & $5 / 421(1.2)$ \\
\hline Other injuries & $265 / 8,729(3)$ \\
Skin injuries & $151 / 265(57)$ \\
\hline
\end{tabular}

Statistics presented: $\mathrm{n}(\%)$. One patient could have suffered from multiple thoracic injuries, therefore the total of injuries $(8,729)$ presented in the table is greater than the number of $\operatorname{AIS}_{\text {Thorax }} \geq 2$ patients $(6,382)$.

$\mathrm{AIS}_{\text {Thorax }} \geq 2$ group: multi-trauma patients presenting with at least one thoracic injury AIS $\geq 2$. 
Table 4. Incidence of concomitant extra-thoracic injuries between $\mathrm{AIS}_{\text {Thorax }} \geq 2$ group and $\mathrm{AIS}_{\text {Thorax }}<2$ group 


$$
\begin{array}{llll}
\operatorname{AIS} \geq 2 & \text { AIS }_{\text {Thorax }} \geq 2 & \text { AIS }_{\text {Thorax }}<2 & p \text { - } \\
\text { group }(n= & \text { group }(13.8 \%, n=6,382) & \text { group }(86.2 \%, n=40,144) & \text { value } \\
46,526) & &
\end{array}
$$

Head

$\begin{array}{llll}\text { AIS }=2 & 8,934(19.2) & 587(9.2) & 8,347(20.8) \\ \text { AIS } \geq 3 & 3,162(6.8) & 1,268(19.9) & 1,894(4.7) \\ \text { No injury } & 34,430(74.0) & 4,527(70.9) & 29,903(74.5)\end{array}$

Face

AIS $=2$

1,995 (4.3)

$384(6.0)$

1,611 (4.0)

AIS $\geq 3$

$186(0.4)$

44,345 (95.3)

Neck

AIS $=2$

$73(0.2)$

AIS $\geq 3$

$59(0.1)$

46,394 (99.7)

No injury

Abdomen/pelvis

AIS $=2$

AIS $\geq 3$

No injury

Spine

AIS $=2$

AIS $\geq 3$

No injury

Upper extremity

AIS $=2$

AIS $\geq 3$

No injury

Lower extremity

AIS $=2$

AIS $\geq 3$

No injury
10,166 (21.9)

$5,032(10.8)$

1,082 (2.3)

1,005 (2.2)

44,439 (95.5)

2,707 (5.8)

731 (1.6)

43,088 (92.6)

15,675 (33.7)

$37,488(59.1)$

$31,328(67.3)$
3,363 (7.2)
93 (1.5)

5,905 (92.5)

539 (8.4)

604 (9.5)

$5,239(82.1)$

$35(0.5)$

$33(0.3)$

6,314 (98.9)

$5.239(82.1)$

717 (11.2)

322 (5.0)

5,345 (83.7)

$93(0.2)$

38,440 (95.8)

$<0.001$

$38(0.1)$

$26(0.1)$

40,080 (99.8)

$<0.001$

543 (1.4)

401 (1.0)

$39,200(97.6)$

$<0.001$

1,990 (5.0)

409 (1.0)

37,745 (94.0)

$<0.001$

14,416 (35.9)

2,909 (7.2)

22,819 (56.8)
9,507 (23.7)

4,045 (10.1)

26,592 (66.2) 
Skin
AIS $=2$
$27(0.06)$
$3(0.05)$
$24(0.06)$
AIS $\geq 3$
42 (0.09)
$2(0.03)$
40 (0.09)
No injury
46,457 (99.85)
6,377 (99.92)
$40,080(99.85)$

Statistics presented: n (\%)

AIS $\geq 2$ group: multi-trauma patients presenting with at least one injury AIS $\geq 2$.

$\mathrm{AIS}_{\text {Thorax }} \geq 2$ group: multi-trauma patients presenting with at least one thoracic injury AIS $\geq 2$; AIS Thorax $<2$ group: multi-trauma patients presenting with at least one injury AIS $\geq 2$ but not in the thoracic region; AIS: abbreviated injury scale.

\section{Figures}

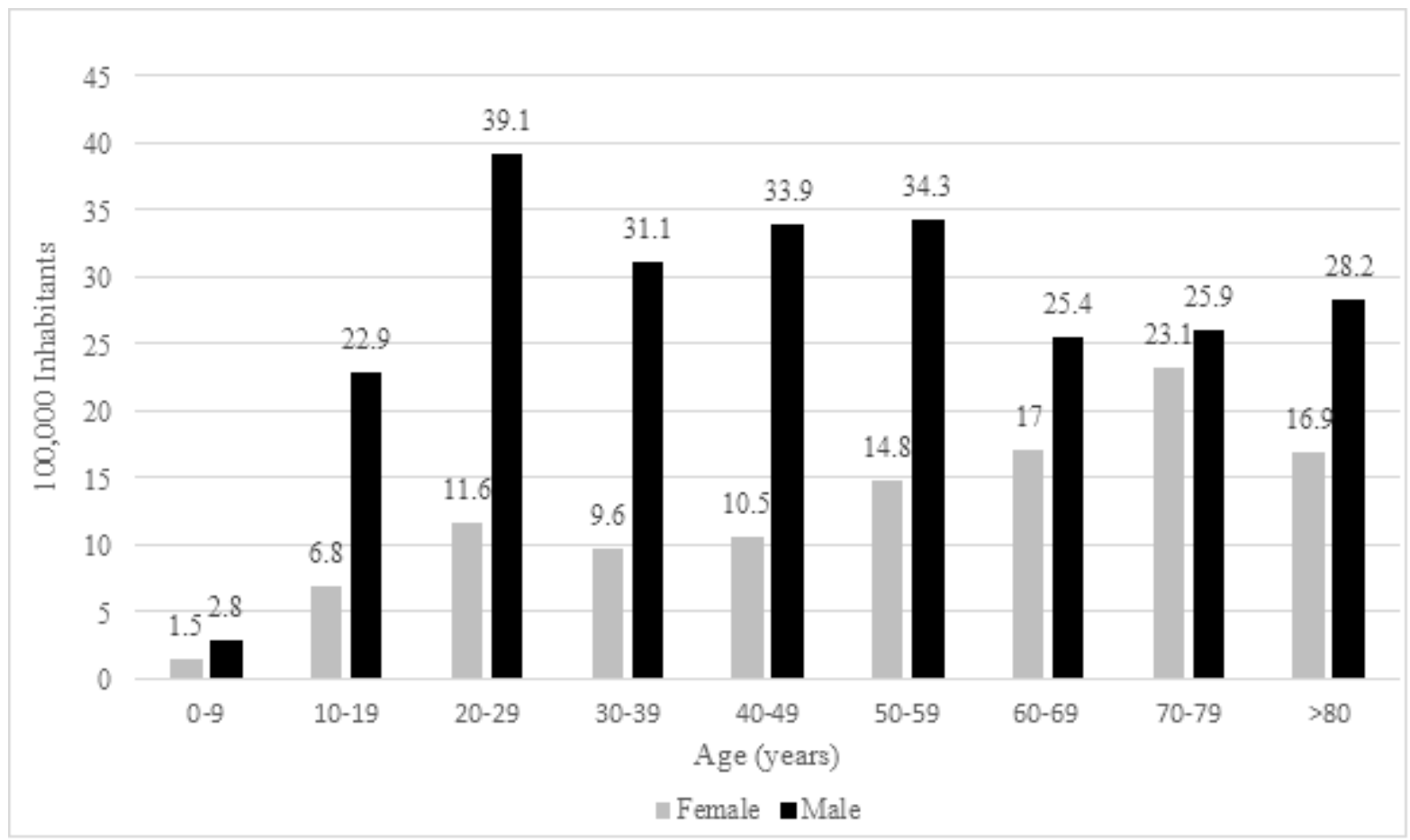

\section{Figure 1}

Title: Road traffic accident among AISThorax $\geq 2$ group per 100,000 inhabitants in the Rhône area population. Legend: Subgroups according to the age. AISThorax $\geq 2$ group: multi-trauma patients presenting with at least one thoracic injury AIS $\geq 2$ 


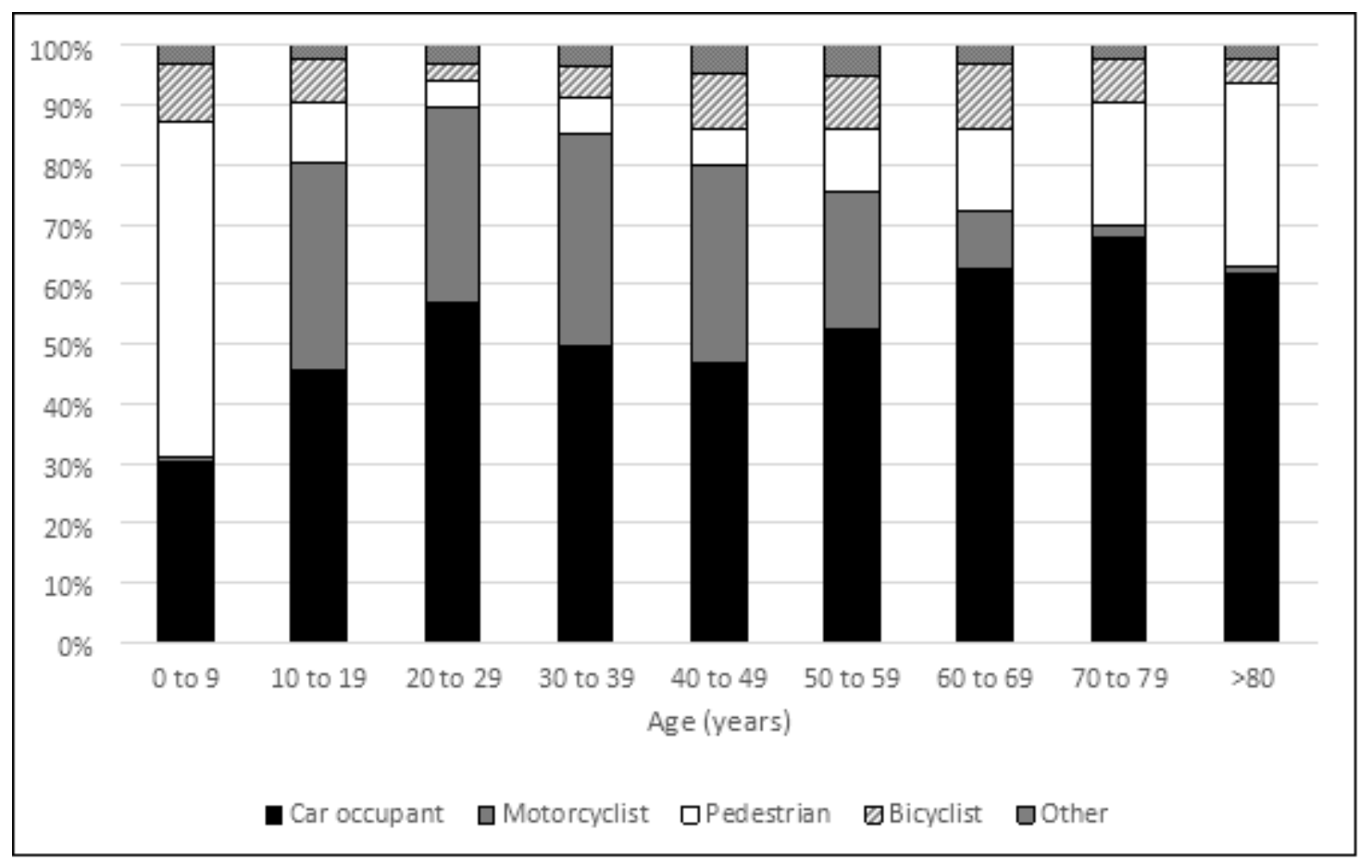

\section{Figure 2}

Title: Road user category distribution according to age in the AISThorax $\geq 2$ group Legend: AISThorax $\geq 2$ group: multi-trauma patients presenting with at least one thoracic injury AIS $\geq 2$.

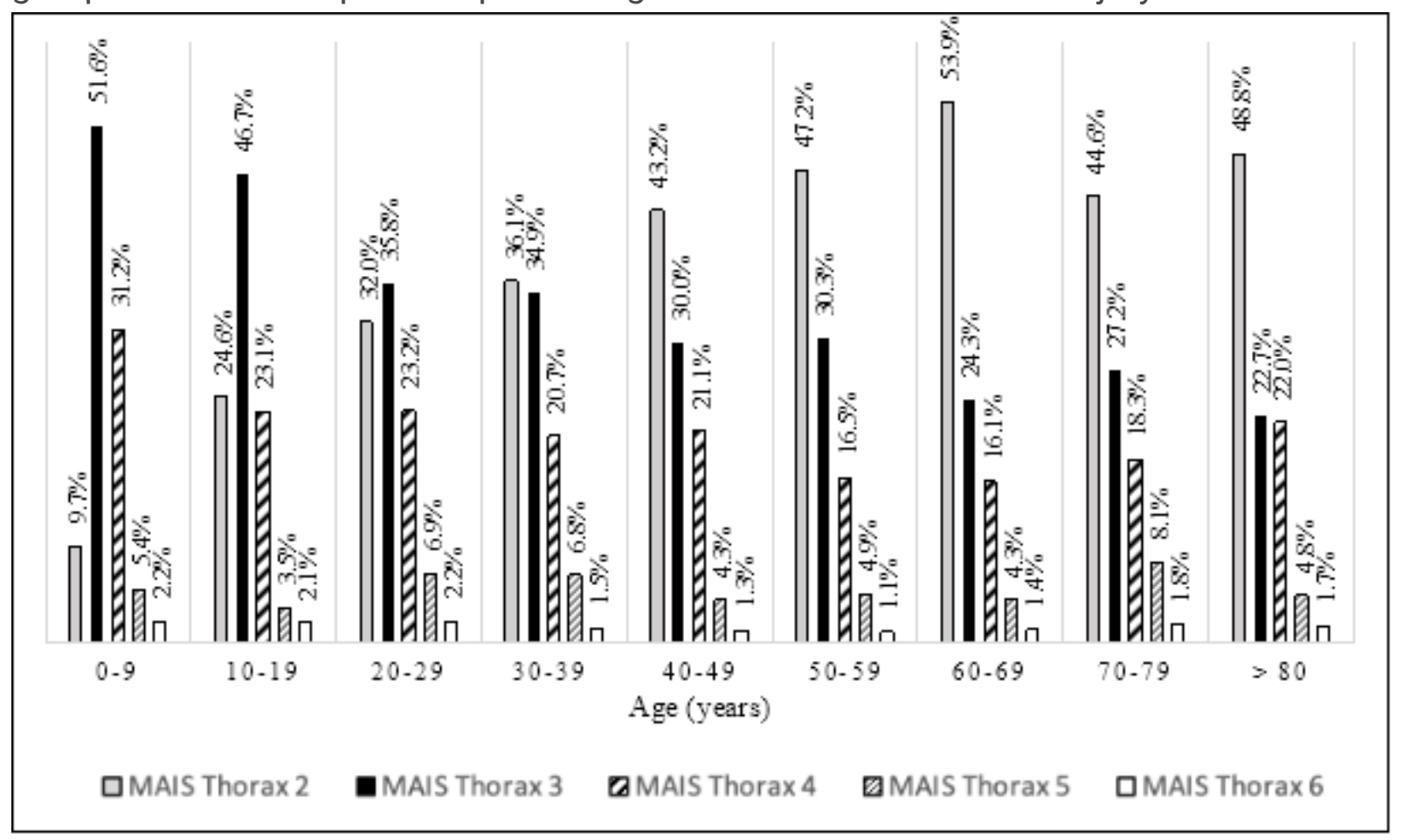

Figure 3

Title: Thoracic maximum abbreviated injury scale distribution according to age in the AISThorax $\geq 2$ group. Legend: AISThorax $\geq 2$ group: multi-trauma patients presenting with at least one thoracic injury AIS $\geq 2$, MAIS: maximum abbreviated injury scale 